\title{
Observations of magnetic flux ropes during magnetic reconnection in the Earth's magnetotail
}

\author{
A. L. Borg ${ }^{1}$, M. G. G. T. Taylor ${ }^{1}$, and J. P. Eastwood ${ }^{2}$ \\ ${ }^{1}$ ESTEC/European Space Agency, Noordwijk, The Netherlands \\ ${ }^{2}$ The Blackett Laboratory, Imperial College London, London SW7 2AZ, UK
}

Correspondence to: A. L. Borg (anette.1.borg@gmail.com)

Received: 6 September 2011 - Revised: 14 April 2012 - Accepted: 16 April 2012 - Published: 3 May 2012

\begin{abstract}
We present an investigation of magnetic flux ropes observed by the four Cluster spacecraft during periods of magnetic reconnection in the Earth's magnetotail. Using a list of 21 Cluster encounters with the reconnection process in the period 2001-2006 identified in Borg et al. (2012), we present the distribution and characteristics of the flux ropes. We find 27 flux ropes embedded in the reconnection outflows of only 11 of the 21 reconnection encounters. Reconnection processes associated with no flux rope observations were not distinguishable from those where flux ropes were observed. Only 7 of the 27 flux ropes show evidence of enhanced energetic electron flux above $50 \mathrm{keV}$, and there was no clear signature of the flux rope in the thermal particle measurements. We found no clear correlation between the flux rope core field and the prevailing IMF $B_{\mathrm{y}}$ direction.
\end{abstract}

Keywords. Magnetospheric physics (Magnetotail) - Space plasma physics (Magnetic reconnection)

\section{Introduction}

The near-Earth neutral line, or NENL, model (e.g. Baker et al., 1996) describes how a thinning of the magnetotail crosstail current sheet can lead to near-Earth magnetic reconnection of the closed magnetic field lines in the plasma sheet. Such magnetic reconnection sites have been associated with the formation of helical magnetic field flux ropes: either as plasmoids produced by multiple X-line reconnection (MXR) (Hughes and Sibeck, 1987; Slavin et al., 2003a) or as secondary magnetic islands formed in the unstable electron current layer of a single reconnection site (Daughton et al., 2006; Drake et al., 2006b).
Plasmoid formation and ejection in the magnetotail under the MXR scenario is facilitated by differing reconnection rates (Schindler, 1974). The X-line with the highest reconnection rate finishes reconnecting closed plasma sheet field lines before the other $\mathrm{X}$-lines and starts reconnecting the open field lines of the lobe. This lobe reconnection produces high velocity outflows that sweep the slower reconnecting Xlines and their intermittent plasmoids away in the earthward and/or tailward directions. Spacecraft observations of magnetic flux ropes have been interpreted as evidence for MXR (e.g. Slavin et al., 2003a; Deng et al., 2004; Eastwood et al., 2005), although other observations have pointed to a single reconnection site as the source of observed flux ropes (Eastwood et al., 2007; Teh et al., 2010). In the single reconnection site scenario, the electron current layer becomes elongated and unstable to the tearing mode, causing repeated formation of secondary islands that are ejected from the $\mathrm{X}$-line. Drake et al. (2006b) suggests that bursty ion reconnection outflow is a signature of the secondary island formation and ejection.

Most MXR and secondary island scenarios demand the existence of a dawn-dusk magnetic guide field in the magnetotail to explain the production of helical- shaped flux ropes (although some simulations have suggested that secondary islands can also form without the presence of such a guide field (Daughton et al., 2006)). This dawn-dusk magnetic field component $\left(B_{\mathrm{y}}\right)$ has been found to correlate with the interplanetary magnetic field (IMF) $B_{\mathrm{y}}$ (Hughes and Sibeck, 1987). More recently, Moldwin and Hughes (1992) found that the polarity of the $B_{\mathrm{y}}$ component of the flux rope itself (the core field) had the same polarity as the IMF $B_{\mathrm{y}}$ component in $87 \%$ of 39 events, and the magnitude of the core field was larger than the IMF $B_{\mathrm{y}}$ in all but one event. 


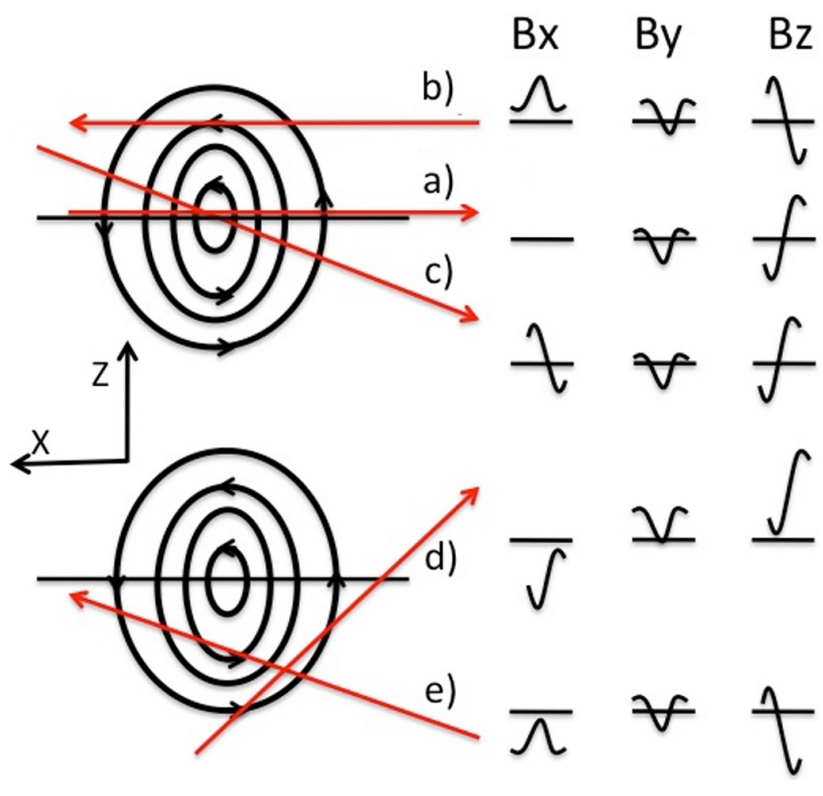

Fig. 1. Sketches of flux ropes observed in the XZ plane (black circular lines and the current sheet (black line) with examples of trajectories across a spacecraft (red lines). The corresponding magnetic field signatures are found to the right of the figure. The core field is assumed to be negative, using our coordinate system.

Magnetic flux ropes in the magnetotail are most frequently identified in the spacecraft data by a bipolar variation in the GSM/GSE $B_{\mathrm{Z}}$ component and a strong core field dominating the $B_{\mathrm{y}}$ component at the center of the bipolar $B_{\mathrm{Z}}$ signature. The bipolar $B_{\mathrm{Z}}$ signature can change from negative to positive values or vice versa, depending on the direction of flux rope movement in the GSM/GSE X-direction across the spacecraft. The direction of movement is most often determined by the flux rope's position on the earthward or tailward side of the nearby X-line(s), as it is embedded in the reconnection outflow. If the plasma sheet or the flux rope path across the spacecraft is strongly tilted, the bipolar signature may not change polarity in GSM/GSE coordinates. The $B_{\mathrm{x}}$ component may at the same time experience a local minimum or maximum, or it may change polarity, depending on the flux rope's trajectory across the spacecraft. This variability in the $B_{\mathrm{x}}$ signature means the magnetic field magnitude may either display a local maximum or a minimum at the center of the flux rope.

If a flux rope is embedded in a reconnection ion outflow, either as a plasmoid or as an ejected secondary island, it will move with the same speed as the flow across the spacecraft (which moves slowly in comparison). Because of the geometry of the magnetic field at the X-line site, we can then expect the spacecraft to observe a negative to positive (or positive to more positive or negative to less negative) bipolar $B_{\mathrm{Z}}$ signature on the earthward side of an $\mathrm{X}$-line $\left(V_{\mathrm{x}}\right.$ ions $\left.>0\right)$ and an opposite signature when on the tailward side $\left(V_{\mathrm{X}}\right.$ ions $\left.<0\right)$ (e.g. Slavin et al., 2003a).
In Fig. 1 we present some examples of flux rope crossings and sketches of the corresponding expected magnetic field signatures. Here, the black circular lines represent magnetic field lines in 2-D and the red lines the spacecraft trajectory relative to the flux rope. The horizontal black line at the middle of the flux rope symbolizes the current sheet. The X component is in the direction of the Earth along the current sheet and the $\mathrm{Y}$ and $\mathrm{Z}$ axes complete the left handed orthogonal set, with the current sheet contained in the $\mathrm{X}$-Y plane. In this construction, the core field is chosen so that it is pointing in the negative $\mathrm{Y}$ direction. The sketches of $B_{\mathrm{x}}, B_{\mathrm{y}}$ and $B_{\mathrm{Z}}$ contain the signatures of the flux rope crossings as well as a sample of the background magnetic field at the entry and exit from the flux rope. The background magnetic field $\mathrm{Y}$ component is chosen so that it is pointing in the positive direction.

Crossing a occurs at the center of the plasma sheet, along the current sheet, where $B_{\mathrm{x}}$ is close to zero both outside and inside of the flux rope. The spacecraft observes the maximum value of the core field $\left|B_{\mathrm{y}}\right|$, because it crosses the middle of the flux rope. The $B_{\mathrm{Z}}$ bipolar signature in this case changes from negative to positive and is relatively symmetric around zero. In crossing b, the spacecraft is located at a distance from the current sheet. The core field is observed in the $B_{\mathrm{y}}$ measurements, but the observation no longer represents the maximum magnitude of the core field. During the passage of the flux rope, $B_{\mathrm{x}}$ will stay positive (the crossing occurs in the Northern Hemisphere) but will change from lower values at the edges of the rope to peaks in the middle. The direction of movement is reversed compared to crossing a; hence, the $B_{\mathrm{Z}}$ bipolar signature varies from positive to negative values. The bipolar signature is still symmetric around zero, because the points of entry and exit are situated at an equal distance from the current sheet. During crossing $\mathrm{c}$ the spacecraft no longer stays in one hemisphere, but traverses the center of the plasma sheet. Consequently, the $B_{\mathrm{x}}$ signature changes from positive to negative values. The spacecraft observes the center point of the flux rope, causing the core field observed in $B_{\mathrm{y}}$ to represent the maximum magnitude core field as in crossing $\mathrm{b}$ and the $B_{\mathrm{Z}}$ bipolar signature to be symmetric around zero. Crossing $\mathrm{d}$ and e both occur in one hemisphere only and the spacecraft does not observe the center point of the flux rope, where the core field is strongest. During crossing $\mathrm{d}$ the spacecraft observes only positive values of $B_{\mathrm{Z}}$ and only negative values of $B_{\mathrm{x}}$. The $B_{\mathrm{Z}}$ bipolar signature is therefore shifted to positive values. $B_{\mathrm{X}}$ changes from a maximum at the start of the crossing to a minimum at the end. In crossing e the $B_{\mathrm{Z}}$ bipolar signature is shifted to mostly negative values. This happens because the spacecraft stays in one hemisphere and the entry and exit points are situated at different distances from the current sheet. $B_{\mathrm{x}}$ is negative throughout the crossing, but experiences a minimum during the crossing when the magnetic field lines are almost vertical.

A bipolar $B_{\mathrm{Z}}$ variation can be caused by phenomena in the magnetotail other than a flux rope crossing, e.g. by transient 
reconnection (Slavin et al., 2005), field-aligned current filaments at the flanks of bursty bulk flows (BBFs) (Snekvik et al., 2007), an undulating current sheet under the presence of an ambient $B_{\mathrm{y}}$ field component (Nakagawa and Nishida, 1989) or the twisting of a reconnection outflow (Shirataka et al., 2006). Multi-spacecraft measurements can help avoid incorrect identification of these structures as a flux rope. A strong core field $B_{\mathrm{y}}$ component should be present at the center of the structure, and multi-spacecraft data should ideally be used in combination with the predicted signatures of different flux rope crossing trajectories and spacecraft positions to check whether they are all consistent with the expected signatures.

The flux rope core field is generally considered to peak at the center of the $B_{\mathrm{Z}}$ bipolar signature (e.g. Hughes and Sibeck, 1987; Slavin et al., 2003a). However, double peak core fields have been found in both simulations and observations (Chen et al., 2007; Lui et al., 2007; Liu et al., 2009). Both the $B_{\mathrm{z}}$ bipolar signature and the $B_{\mathrm{y}}$ peak may deviate from the expected sinusoidal and peak shape and display more structure closer to the center of the flux rope. Lui et al. (2007) suggest that while the outer layers of a flux rope have the expected helical shape, the inner layers may have a more irregular magnetic structure. Other reported flux rope properties are increased electron density inside the rope (Chen et al., 2007), increased ion density in front of the rope (Slavin et al., 2003a), low plasma beta values inside a flux rope occurring on the earthward side of an X-line (Slavin et al., 2003a), electron acceleration inside the flux rope (Drake et al., 2006a; Chen et al., 2007), a bipolar $E_{\mathrm{y}}$ (electrical field Y component) signature (Eastwood et al., 2007; Teh et al., 2010) and the occurrence of most flux ropes at the start of BBFs (Slavin et al., 2003a).

In this paper we investigate a special set of flux ropes, namely flux ropes that are identified in the time intervals of near-Earth reconnection process encounters by the Cluster spacecraft in the Earth's magnetotail. We have used a list of 21 encounters during the years 2001-2006, which can be found in Borg et al. (2012). To our knowledge, this is the first survey of such flux ropes. These flux ropes are of special interest, because their connection to the nearby reconnection site is fairly certain, which means they are probably unaffected by non-reconnection related processes that would alter their properties (e.g. compressions and distortions). The lack of observations of flux ropes during some reconnection process encounters also raises questions: "Do the reconnection encounters where no flux ropes are observed differ in some way from the encounters where flux ropes are observed?" and "Why are more flux ropes observed during some reconnection encounters than during others?" The encounters on the list have been analyzed by various authors (e.g. Eastwood et al., 2010a) and in most cases are associated with the observation of a single X-line moving across the spacecraft; although, it cannot be discounted that there may have been short-lived additional X-lines present that were not observed by the spacecraft.

\section{Observations}

The Cluster data used to identify and analyze the time intervals studied in this paper were obtained from the Cluster Active Archive (Laakso et al., 2010). The magnetic field data were provided by the Flux-Gate Magnetometer (FGM) experiment (Balogh et al., 2001), the ion plasma data were measured by the Cluster Ion Spectrometry (CIS) experiment (Rème et al., 2001), the electric field and potential came from the Electric Field and Wave (EFW) instrument (Gustafsson et al., 2001) and the electron data are from the Plasma Electron and Current Experiment (PEACE) (Johnstone et al., 1997) and from the Research with Adaptive Particle Imaging Detectors instrument (RAPID) (Wilken et al., 2001). All data are presented in the GSM coordinate system except the electric field data, which are in the local spacecraft spin reference coordinate system, ISR2. The difference between ISR2 and the GSE coordinate system is a small (2-7 degrees) rotation around the $\mathrm{Y}$ axis. We note that the CIS instrument does not function on Cluster 2.

We surveyed time intervals identified as reconnection process encounters (listed by Borg et al. (2012)) for signatures of flux ropes, using full resolution (characteristic time between data samples: $0.0446 \mathrm{~s}$ ) magnetic field data. Most of these encounters have been studied by other authors, e.g. Eastwood et al. (2007); Asano et al. (2008). During all the encounters the spacecraft were situated in the plasma sheet or in the plasma sheet boundary layer (PSBL). The position of the spacecraft relative to the lobe/plasma sheet/PSBL was determined using the plasma beta parameter, where a plasma beta larger than 0.3 corresponds to the plasma sheet proper, while plasma beta values in the range $0.1-0.3$ are associated with the PSBL (e.g. Baumjohann et al., 1990; Mukai et al., 1996). During periods where the plasma beta could not be calculated (due to missing data or instrument error), changes in plasma density and temperature were used for identification. When the spacecraft encountered the lobe, the density and temperature dropped sharply to values below those associated with the plasma sheet $\left(n_{\mathrm{i}} \sim 0.05 \mathrm{~cm}^{-3}, T_{\mathrm{i}} \sim 50 \mathrm{MK}\right.$, e.g. Eastwood et al. (2009). The signatures used to identify the flux ropes were (1) a bipolar GSM $B_{\mathrm{Z}}$ variation, (2) a maximum or minimum (one or two peaks) in $B_{\mathrm{y}}$ occurring around the center of the bipolar $B_{\mathrm{Z}}$ variation, and (3) a minimum or maximum in $|B|$. These signatures should preferably be observed by more than one spacecraft to enable a multi-spacecraft analysis, but a few observations by single spacecraft positioned at the center of the plasma sheet were also accepted if the bipolar $B_{\mathrm{Z}}$ signature changed polarity in the GSM coordinate system and $B_{\mathrm{y}}$ showed a clear, strong central peak. A multi-spacecraft analysis was employed in most cases to try and exclude other possible magnetic field 

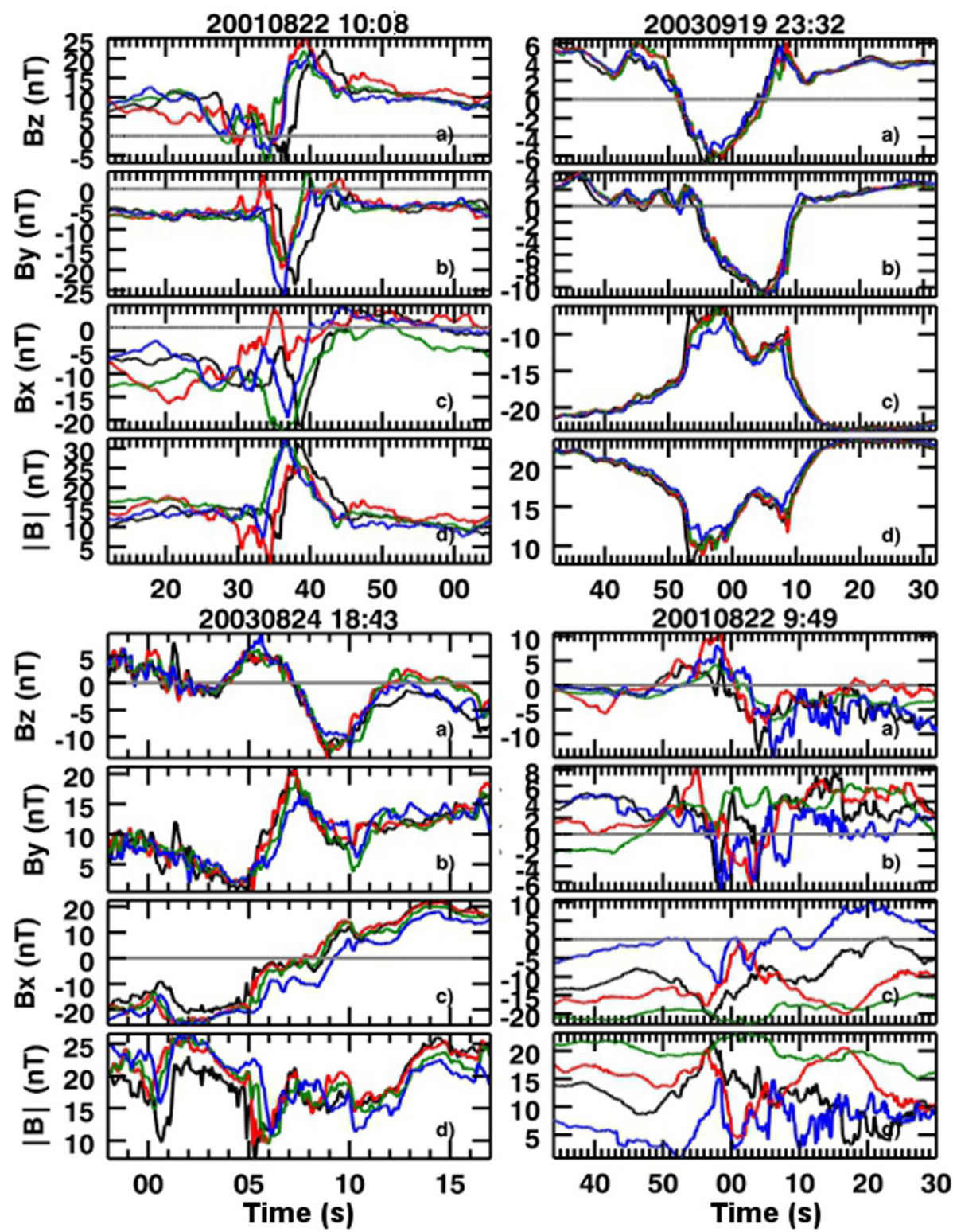

Fig. 2. Flux rope signatures observed on 22 August 2001, 19 September 2003, 24 August 2003 and 22 August 2001 by the four Cluster spacecraft (SC1 black, SC2 red, SC3 green and SC4 blue). The X-axes show seconds after 10:08, 23:32, 18:42 and 09:49 GMT, respectively. (a) The $B_{\mathrm{Z}}$ component showing the bipolar signature, (b) the $B_{\mathrm{y}}$ component containing the core field, (c) the $B_{\mathrm{X}}$ component and (d) the magnetic field magnitude reaching a local maximum or minimum.

structures as the source of the bipolar $B_{\mathrm{Z}}$ variation. In some cases, where the current sheet was strongly tilted with respect to the GSM coordinate system as determined by the minimum variance analysis (MVA) and/or timing analysis, it was necessary to establish a new coordinate system based on the direction of minimum variance to check whether the $B_{\mathrm{Z}}$ bipolar signature changed polarity or not in the current sheet reference frame. The $B_{\mathrm{Z}}$ signature was not required to be symmetric around zero, because the degree of symmetry is decided by the trajectory of the flux rope across the spacecraft, as shown above.
Four examples of flux rope observations by the four Cluster spacecraft are shown at full resolution in the GSM coordinate system in Fig. 2. The 22 August 2001, 10:08 flux rope has been studied previously by Slavin et al. (2003b) and Möstl et al. (2009). In Fig. 2a the bipolar $B_{\mathrm{Z}}$ signature is clearly visible, in Fig. $2 \mathrm{~b}$ the $B_{\mathrm{y}}$ component reaches a maximum value, the core field, at the center of the $B_{\mathrm{Z}}$ dipolar variation, in Fig. $2 \mathrm{c}$ the $B_{\mathrm{x}}$ component displays a local maximum and in Fig. $2 d$ the magnetic field magnitude reaches a local maximum. Timing analysis and MVA of time intervals outside the flux rope suggested that the current sheet normal was 

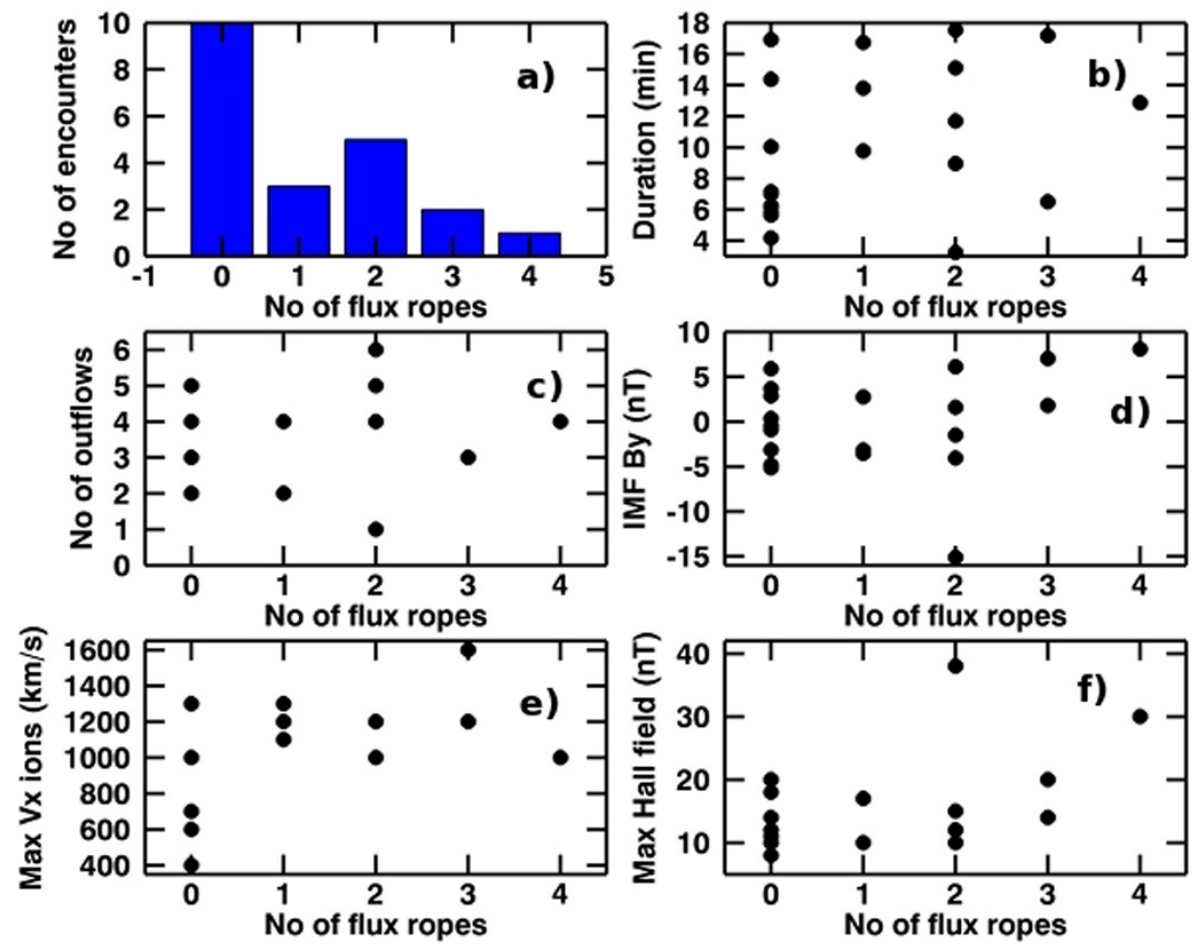

Fig. 3. The number of flux ropes observed during a SC4 X-line encounter versus (a) the total number of encounters during which this number of flux ropes was observed, (b) the total duration (in minutes) of reconnection outflow observed during the encounter, (c) the number of separate outflow episodes observed during the encounter, (d) the $3 \mathrm{~h}$ average of the interplanetary magnetic field (IMF) Y component at the bow shock nose before the start of the encounter, (e) the maximum magnitude of the ion outflow velocity (GSM $V_{\mathrm{X}}$ component) during the $\mathrm{X}$-line encounter and (f) the maximum magnitude of the Hall magnetic field (GSM $B_{\mathrm{y}}$ component).

tilted in the $\mathrm{Y}$ direction, in this case causing the $B_{\mathrm{Z}}$ bipolar signature in GSM coordinates to be shifted to more positive values. The flux rope was positioned at the start of a positive (earthward moving) ion reconnection outflow, on the earthward side of an X-line site. Timing analysis of the flux rope observation itself (using the data from all four Cluster spacecraft) showed that the flux rope structure moved across the spacecraft in the earthward direction at about the same speed as the ion outflow (Möstl et al., 2009). The $B_{\mathrm{Z}}$ bipolar signature changed from negative to positive values, as would be expected on the earthward side of an X-line.

The 19 September 2003 flux rope was characterized by similar signatures as the 22 August 2001, 10:08 flux rope. $B_{\mathrm{Z}}$ changed polarity from negative to positive during a earthward reconnection outflow (not shown). The core field is negative and strong compared to the background field. The $24 \mathrm{Au}-$ gust 2003 flux rope was embedded in a tailward reconnection outflow (Khotyaintsev et al., 2010). The bipolar $B_{\mathrm{Z}}$ signature is almost symmetric around zero and changes from positive to negative, as expected. The second flux rope observed on 22 August 2001, at around 09:50 GMT, has been described by Lui et al. (2007). The signatures were more complex and messy, containing both single and double peak core fields. It was embedded in a tailward plasma flow, and the core field was antiparallel to the background magnetic field Y component.

\section{Distribution of flux ropes}

In Fig. 3 the number of flux ropes observed by Cluster SC4 during a reconnection process encounter is compared to (a) the total number of encounters during which this number of flux ropes were observed, (b) the total duration (in minutes) of reconnection ion outflow observed during the encounter, (c) the number of separate outflow episodes observed during the encounter, (d) the $3 \mathrm{~h}$ average of the interplanetary magnetic field (IMF) Y component before the start of the encounter, (e) the maximum magnitude of the ion outflow velocity (GSM $V_{\mathrm{x}}$ component) measured during the $\mathrm{X}$-line encounter and ( $\mathrm{f}$ ) the maximum magnitude of the Hall magnetic field (GSM $B_{\mathrm{y}}$ component) measured by the spacecraft during the reconnection process encounter. SC4 data were chosen because this spacecraft observed the highest number of flux ropes in total. Only flux ropes observed by more than one spacecraft were included in this figure. The same analysis performed on observations by the other spacecraft showed similar results. 


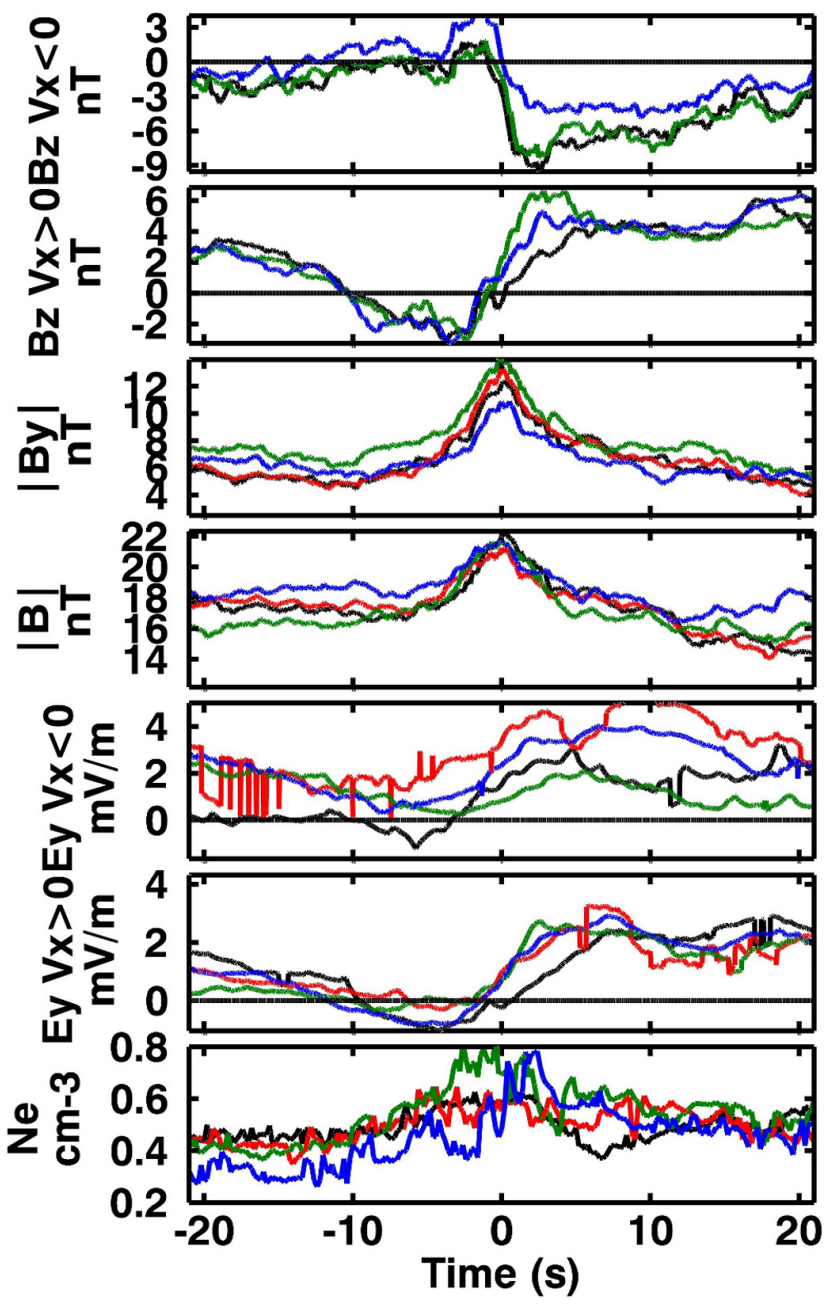

Fig. 4. Data from all spacecraft: SC1 black, SC2 red, SC3 green and SC4 blue. Average epoch presentation of the average of all observed flux ropes: $B_{\mathrm{Z}}$ earthward $(\mathrm{nT})\left(V_{\mathrm{X}}^{\text {ion }}>0\right)$ and tailward (nT) $\left(V_{\mathrm{x}}^{\text {ion }}<0\right)$ of the X-line site, $\left|B_{\mathrm{y}}\right|(\mathrm{nT}),|B|(\mathrm{nT})$ and $E_{\mathrm{y}}$ earthward $\left(\mathrm{mV} \mathrm{m}^{-1}\right), E_{\mathrm{y}}$ tailward $\left(\mathrm{mV} \mathrm{m}^{-1}\right)$ of the X-line site (full resolution electric field filtered with a low pass filter) and the electron density $\left(\mathrm{cm}^{-3}\right)$. The time interval at the X-axis starts at $20 \mathrm{~s}$ before the middle of the flux rope is observed (at zero seconds) and stops at $20 \mathrm{~s}$ after.

11 of the 21 reconnection ion outflow encounters were coincident with a total of 27 embedded flux ropes (listed in Table 1). The remaining 10 contained no clear flux rope signatures at all. These (low) numbers are reflected in the distribution of data points in Fig. 3. The number of flux ropes identified during an encounter seemed to be unrelated to the number of separate outflows ("bursty-ness") observed during that encounter (Fig. 3c) and also unrelated to the total duration of the reconnection outflows (Fig. 3b). This suggested that the number of flux ropes observed during an encounter with a reconnection process is not determined by the time interval in which the reconnection process is active in the vicinity of the spacecraft before it either ceases reconnecting or moves away, down the magnetotail. It also did not agree with the suggestion by Drake et al. (2006b) that a bursty ion reconnection outflow is a clear signature of multiple secondary island ejections. Furthermore, a correlation analysis of the data shown in Fig. 3d did not support the hypothesis of a linear correlation between the number of flux ropes and the polarity (or magnitude) of the IMF $B_{\mathrm{y}}$ component. Nor was there any clear connection between the number of flux ropes and the maximum ion outflow velocity (Fig. 3e) or the maximum magnitude of the Hall quadrupole magnetic field (Fig. 3f). Another interesting point is that the reconnection process encounters during which no flux ropes were observed did not display any clear features in Fig. 3a-f that distinguish them from the X-line encounters where flux ropes were observed.

\section{Flux rope epoch analysis}

To investigate the general properties of flux ropes in reconnection outflows, we started by looking at the average flux rope qualities using a superposed epoch analysis, where zero seconds marks the middle of the flux rope signature. In Fig. 4, an epoch plot of the average for all observed flux ropes of (from the top) $B_{\mathrm{Z}}$ tailward $\left(V_{\mathrm{x}}^{\text {ion }}<0\right.$ ) and earthward ( $V_{\mathrm{x}}^{\text {ion }}>0$ ) of the X-line site, $\left|B_{\mathrm{y}}\right|,|B|, E_{\mathrm{y}}$ earthward, $E_{\mathrm{y}}$ tailward (full resolution electric field filtered with a low pass filter to remove noise) and the electron density calculated using the spacecraft potential (Pedersen et al., 2008) is shown from $20 \mathrm{~s}$ before to $20 \mathrm{~s}$ after the middle of the flux rope observation. The aim of Figs. 4 and 5 is to investigate the general shape and timing of the flux rope signatures, not their magnitudes. For these reasons, and because the errors were found to roughly duplicate the shape of the averages, no error bars are included in the figures. The black line shows data from SC1 (20 flux ropes), the red from SC2 (23 flux ropes), the green from SC3 (23 flux ropes) and the blue from SC4 (24 flux ropes). We can see the expected $B_{\mathrm{Z}}$ bipolar positive to negative signature during tailward $V_{\mathrm{x}}^{\text {ion }}<0$ reconnection outflow for all spacecraft. The signature is shifted to negative values, showing that asymmetric flux rope crossings dominate. The negative to positive $B_{\mathrm{Z}}$ bipolar signature during earthward $V_{\mathrm{x}}^{\text {ion }}>0$ outflow is also clearly visible.

The core field is visible as a single peak in the $\left|B_{\mathrm{y}}\right|$ measurements at around zero seconds for all SC. $|B|$ data display on average a maximum peak in the middle of the flux rope. The electric field $E_{\mathrm{y}}$ component in flux ropes on the earthward side of an X-line (when $V_{\mathrm{X}}^{\text {ion }}>0$ ) has a clear bipolar signature, changing polarity close to zero seconds from negative to positive, while the $E_{\mathrm{y}}$ measured during flux rope crossings at the tailward side has a similar but less clear signature. For all the spacecraft the electron density is enhanced at approximately the middle of the average flux rope. 
Table 1. Flux ropes observed during reconnection process encounters in the magnetotail.

\begin{tabular}{|c|c|c|c|c|c|c|}
\hline $\begin{array}{l}\text { Reconnection } \\
\text { encounter }\end{array}$ & $\begin{array}{l}\text { Flux } \\
\text { rope }\end{array}$ & Date & $\begin{array}{l}\text { Time first } \\
\text { observed }\end{array}$ & Spacecraft & $\begin{array}{l}\text { Double } \\
\text { peak } B_{\mathrm{y}}\end{array}$ & $\begin{array}{l}\text { Enhanced } \\
\text { e flux }\end{array}$ \\
\hline \multirow{5}{*}{$\mathrm{a}$} & 1 & 22 Aug 2001 & $09: 42: 46$ & $\mathrm{SC} 3$ & No & No \\
\hline & 2 & 22 Aug 2001 & 09:46:03 & $\mathrm{SC} 1$ & No & No \\
\hline & 3 & 22 Aug 2001 & $09: 46: 12$ & $\mathrm{SC} 1,2,4$ & No & No \\
\hline & 4 & 22 Aug 2001 & $09: 49: 54$ & $\mathrm{SC} 1,2,3,4$ & Yes & No \\
\hline & 5 & 22 Aug 2001 & $10: 08: 32$ & $\mathrm{SC} 1,2,3,4$ & No & No \\
\hline \multirow{4}{*}{$\mathrm{b}$} & 6 & 12 Sep 2001 & $13: 09: 44$ & SC3 & No & No \\
\hline & 7 & 12 Sep 2001 & $13: 13: 36$ & $\mathrm{SC} 1,2,4$ & Yes & Yes \\
\hline & 8 & 12 Sep 2001 & $13: 15: 28$ & $\mathrm{SC} 1,2,3,4$ & No & Yes \\
\hline & 9 & 12 Sep 2001 & $13: 17: 26$ & $\mathrm{SC} 1,2,3,4$ & Yes & Yes \\
\hline \multirow{4}{*}{$\mathrm{c}$} & 10 & 1 Oct 2001 & 09:39:22 & $\mathrm{SC} 2,3,4$ & No & No \\
\hline & 11 & 1 Oct 2001 & $09: 47: 40$ & $\mathrm{SC} 2,3,4$ & Yes & Yes \\
\hline & 12 & 1 Oct 2001 & $09: 55: 13$ & $\mathrm{SC} 2,3,4$ & Yes & No \\
\hline & 13 & 1 Oct 2001 & 09:57:12 & $\mathrm{SC} 1,2,3,4$ & Yes & No \\
\hline \multirow{2}{*}{ d } & 14 & 21 Aug 2002 & $07: 53: 40$ & $\mathrm{SC} 1,2,3,4$ & No & No \\
\hline & 15 & 21 Aug 2002 & 08:08:25 & $\mathrm{SC} 4$ & No & No \\
\hline $\mathrm{e}$ & 16 & 18 Sep 2002 & 13:06:37 & $\mathrm{SC} 3,4$ & No & No \\
\hline$f$ & 17 & 2 Oct 2002 & $21: 30: 11$ & $\mathrm{SC} 1,2$ & Yes & No \\
\hline \multirow[b]{2}{*}{$\mathrm{g}$} & 18 & 17 Aug 2003 & $16: 41: 11$ & $\mathrm{SC} 1,2,3,4$ & No & No \\
\hline & 19 & 17 Aug 2003 & $16: 55: 48$ & $\mathrm{SC} 1,2,3,4$ & Yes & No \\
\hline \multirow{2}{*}{ h } & 20 & 24 Aug 2003 & $18: 39: 47$ & $\mathrm{SC} 1,2,3,4$ & No & Yes \\
\hline & 21 & 24 Aug 2003 & $18: 43: 03$ & $\mathrm{SC} 1,2,3,4$ & No & Yes \\
\hline \multirow{3}{*}{$\mathrm{i}$} & 22 & 19 Sep 2003 & $23: 32: 52$ & $\mathrm{SC} 1,2,3,4$ & No & No \\
\hline & 23 & 19 Sep 2003 & $23: 42: 40$ & $\mathrm{SC} 1,2,3,4$ & No & No \\
\hline & 24 & 19 Sep 2003 & $23: 45: 12$ & $\mathrm{SC} 1,2,3,4$ & No & No \\
\hline $\mathrm{j}$ & 25 & 4 Oct 2003 & $06: 28: 13$ & $\mathrm{SC} 1,2,3,4$ & No & Yes \\
\hline \multirow{2}{*}{$\mathrm{k}$} & 26 & 28 Aug 2005 & $23: 43: 51$ & $\mathrm{SC} 3,4$ & Yes & No \\
\hline & 27 & 28 Aug 2005 & 23:54:05 & $\mathrm{SC} 1,2,3,4$ & Yes & No \\
\hline
\end{tabular}

In Fig. 5 we show, from the top, the superposed epoch plot of the plasma beta parameter for flux ropes on the tailward and earthward side of the X-line site, the differential electron flux of the 50.5-68.1 keV energy channel measured by RAPID, the electron anisotropy for all PEACE electron energies $(70 \mathrm{eV}-24 \mathrm{keV})$ defined by (field-aligned flux - perpendicular flux)/(field-aligned flux + perpendicular flux), the ion velocity $\mathrm{X}$-component and the ion density. This figure covers the time range from $120 \mathrm{~s}$ before to $120 \mathrm{~s}$ after the middle of the flux rope observation. The colors are defined as in Fig. 4. The flux rope plasma beta on the tailward side of the $\mathrm{X}$-line has no consistent feature across the spacecraft during the flux rope crossing. On the earthward side there is a local minimum value close to zero seconds for all three spacecraft. As the data resolution is $8 \mathrm{~s}$, it is hard to distinguish any clear features around the flux rope. The $50 \mathrm{keV}$ electron flux seems to reach local maximum value at zero time, although the same value is again reached at about $+55 \mathrm{~s}$ for all SC ex- cept SC1. The electron anisotropy is positive during the time interval; hence, there is a dominance of field-aligned electron flux, and there is no noticeable signature of the flux rope itself. The mean magnitude of the ion velocity $V_{\mathrm{x}}$ component (reconnection ion outflow) is quite high $\left(>300 \mathrm{~km} \mathrm{~s}^{-1}\right)$ at the beginning of the interval and it grows stronger at and shortly after zero time for SC1 and 4, suggesting that on average the flux ropes occur during a reconnection outflow (BBF) or at the start of a flow enhancement. The average ion density does not describe any structure around zero seconds, common to all spacecraft.

\section{Core field}

The core field signature used in this paper includes both a single and a double peak in the GSM $B_{\mathrm{y}}$ component. Lui et al. (2007) and Chen et al. (2007) both report single and double peaks observed simultaneously by the different Cluster 


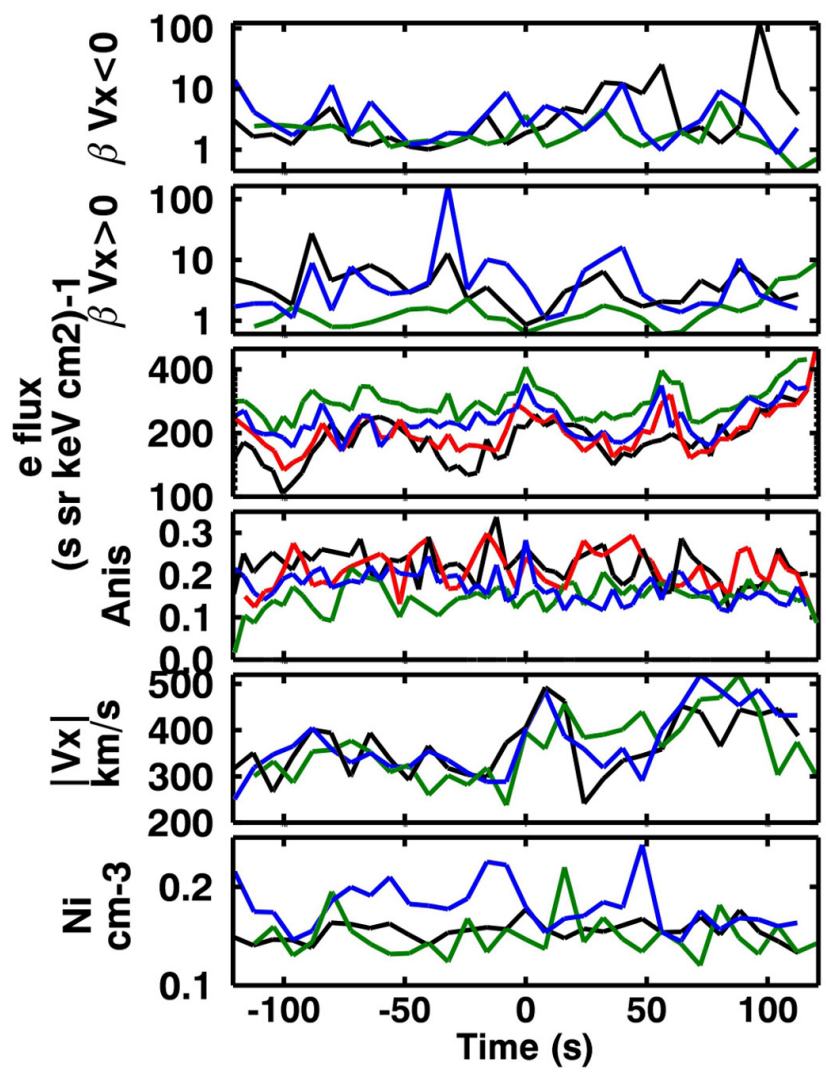

Fig. 5. Data from all spacecraft: SC1 - black, SC2 - red, SC3 green and SC4 - blue. Average epoch presentation of plasma beta parameter for flux ropes on the tailward and earthward side of the $\mathrm{X}$-line, the electron flux $\left(\mathrm{cm}^{-2}(\mathrm{~s} \mathrm{sr} \mathrm{keV})^{-1}\right)$ of the $50 \mathrm{keV}$ energy channel measured by RAPID, the electron anisotropy for all electron energies (field-aligned flux - perpendicular flux)/ (field-aligned flux + perpendicular flux), the $V_{\mathrm{x}}^{\text {ion }}\left(\mathrm{km} \mathrm{s}^{-1}\right)$, the electron density $\left(\mathrm{cm}^{-3}\right)$ calculated using the spacecraft potential (Pedersen et al., 2008) and the ion density $\left(\mathrm{cm}^{-3}\right)$. The $\mathrm{X}$-axis time interval starts at $120 \mathrm{~s}$ before the middle of the flux rope is observed (at zero seconds) and stops at $120 \mathrm{~s}$ after.

spacecraft during the passage of a flux rope across the spacecraft. Out of our 27 identified flux ropes, 11 flux ropes displayed a double peak $B_{\mathrm{y}}$ signature observed by one or more spacecraft (Table 1). An example is shown in Fig. 6. Cluster 2 and Cluster 3 observed a single peak, whereas Cluster 4 observed a double peak. Lui et al. (2007) suggests that the more structured $B_{\mathrm{z}}$ and $B_{\mathrm{y}}$ signatures occur closer to the center of the flux rope (closer to the current sheet). Our analysis of the relative positions of the spacecraft, the maximum core field observed by each spacecraft and the corresponding value of $B_{\mathrm{x}}$ showed that for 7 of the double peak structures, this assumption holds. For the rest of the double peaks, the spacecraft were either situated too close together or the structures were too complicated to clearly identify which spacecraft was situated closest to the current sheet.

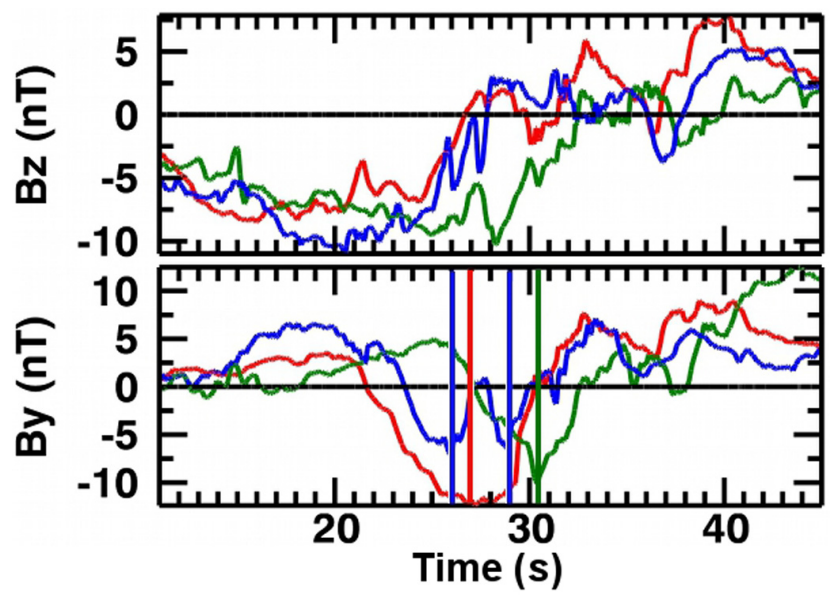

Fig. 6. An example of simultaneous single and double peak $B_{\mathrm{y}}$ core field signatures. The $\mathrm{X}$-axis shows seconds from 09:55:00 UT on 1 October 2001. The $B_{\mathrm{z}}$ bipolar signatures and the $B_{\mathrm{y}}$ signature of a flux rope. SC2 red, SC3 green, SC4 blue. The vertical lines mark the $B_{\mathrm{y}}$ core field peaks.

As discussed above, there are claims that the flux rope core field is derived from the guide field and/or the IMF $B_{\mathrm{y}}$ (e.g. Moldwin and Hughes, 1992). If this is the case, all flux ropes produced at the same magnetotail X-line site (or even in the same area by different $\mathrm{X}$-lines) over a short time interval should have the same polarity core field. The polarity of the core fields should also correlate with the guide field/IMF $B_{\mathrm{y}}$. To test this, we needed to identify the IMF $B_{\mathrm{y}}$ and the guide field prior to the flux rope creation. For this purpose, we used solar wind data from the OMNIWeb service (King and Papitashvili, 2005) that have been time-shifted to the bow shock nose. We then calculated the average and standard deviation of the IMF $B_{\mathrm{y}}$ component during the last $30 \mathrm{~min}$ (Fig. 7a) and $60 \mathrm{~min}$ (Fig. 7b) before the Cluster X-line encounters, reflecting the methods used by Slavin et al. (2003a) and Moldwin and Hughes (1992). Figure 7a and $b$ show plots of the average IMF $B_{\mathrm{y}}$ versus the maximum value of the core field observed for each flux rope. The error bars represent the IMF $B_{\mathrm{y}}$ standard deviation. We note that for 13 of the 27 flux ropes the polarity of the core field was the opposite of the polarity of the IMF $B_{\mathrm{y}}$, even when the errors were taken into account. We also note that the majority of core fields are of negative polarity. Both Moldwin and Hughes (1992) and Slavin et al. (2003a) reported that a majority ( $87 \%$ of 39 and $79 \%$ of 28 ) of the flux ropes in their samples had core field polarities that agreed with the IMF $B_{\mathrm{y}}$ polarity prior to the flux rope observations. The sample sizes, including the sample of 27 flux ropes identified in this paper, were all less than 40 , indicating that a varying degree of agreement is to be expected. An additional point can be made that in this paper the IMF $B_{\mathrm{y}}$ is compared to the maximum of the flux rope core field as measured by the spacecraft, whereas in Slavin et al. (2003a) 


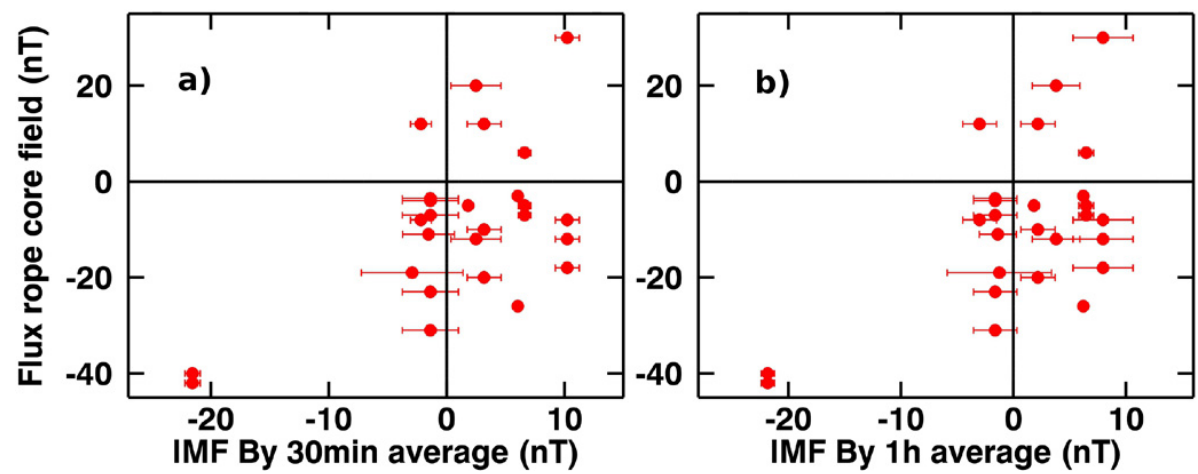

Fig. 7. X-axis: The IMF $B_{\text {y }}$ averaged over the last (a) $30 \mathrm{~min}$ and (b) $60 \mathrm{~min}$ before each Cluster X-line encounter. Y-axis: The maximum core field for each flux rope. The error bars represent the IMF $B_{\mathrm{y}}$ standard deviation. The error in identifying the maximum core field is estimated to be about $1 \mathrm{nT}$.

a fit to a flux rope model was used to find the true peak core field.

The guide field was more difficult to identify. In the literature we have found four different methods for finding the guide field: (1) identifying the GSM/GSE $B_{\mathrm{y}}$ component measured in the plasma sheet just before observation of reconnection outflow(s) (e.g. Retinò et al., 2008), (2) using simultaneous or almost simultaneous magnetic field measurements north and south or the current sheet to identify the plasma sheet coordinate system (e.g. Eastwood et al., 2010b), (3) identifying a constant offset in the quadrupole $B_{\mathrm{y}}$ Hall field measurement during the reconnection outflows (e.g. Wygant et al., 2005) and (4) using minimum variation analysis (MVA) to find the plasma sheet coordinate system (e.g. Eastwood et al., 2007). These methods all have known advantages, but also restrictions and error sources, when applied to data sets. Method 1 can only be used if there is a stable $B_{\mathrm{y}}$ value over an extended time period prior to observation of reconnection outflow. To use method 2 there has to be either simultaneous measurements made in both hemispheres by multiple spacecraft (a condition that is unfortunately seldom met) or one spacecraft must cross the current sheet in a rapid movement from one hemisphere to the other. Both possibilities introduce the problem of choosing the right time intervals to compare in an unstable environment and for the latter, it also ignores any changes occurring in the magnetic field configuration during the current sheet crossing. Method 3 depends on a simple estimate of an offset of the Hall magnetic field, which makes it a highly subjective method, and assumes that the Hall field is unaffected by the presence of the guide field, which is not the case (Eastwood et al., 2010b). Method 4 relies on the MVA analysis producing a valid and stable answer for the period prior to or during the X-line encounter. Choosing a time interval during reconnection outflow observations to use as input in the analysis is a challenge, as the underlying assumption that there must be a direction of maximum and minimum magnetic field variation must be met, and conditions rapidly change in these ar-

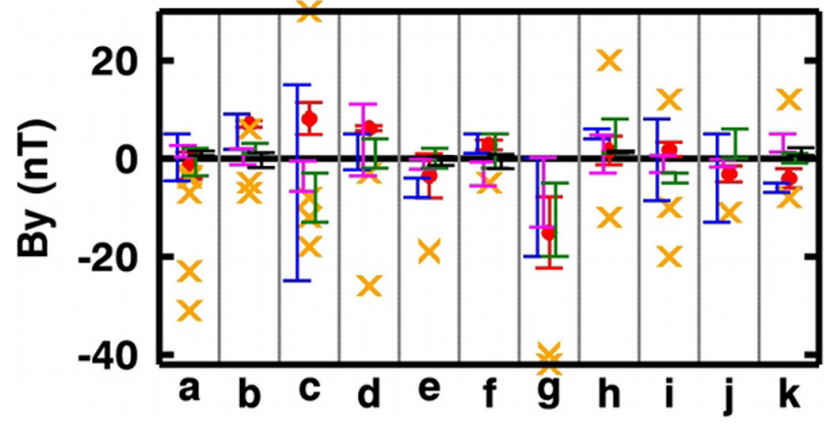

Fig. 8. The range of guide field values for reconnection process encounters $a-k$, found using four different methods (when applicable). The average $3 \mathrm{~h}$ IMF $B_{\mathrm{y}}$ (red dots and error bars) and the maximum core field measured for each flux rope (yellow crosses) are added for comparison. Method 1: blue, method 2: magenta, method 3: green and method 4: black.

eas. Repeating the analysis over a different time interval will often yield a different result, either because of actual, fast changes in the current sheet normal or because of the limitations of the method used. If possible, it can be a better solution to perform the MVA analysis on data from time intervals just before or after observations of reconnection outflows.

When comparing these methods as applied by different authors, it was clear that they did not produce the same results even for the same X-line encounter. The variation in results could be quite large, up to 5 times or more from one method to the next when the authors analyzed the same X-line encounter. Using all four methods (when applicable) multiple times (if possible) on the $11 \mathrm{X}$-line encounters associated with flux rope observations produced a range of results for each method and for each encounter. In Fig. 8, the 11 reconnection process encounters are represented on the $\mathrm{X}$ axis (labeled $\mathrm{a}-\mathrm{k}$ ) and divided by grey vertical lines. The range of results for each method (method 1: blue, method 2: magenta, method 3: green and method 4: black) is shown for 


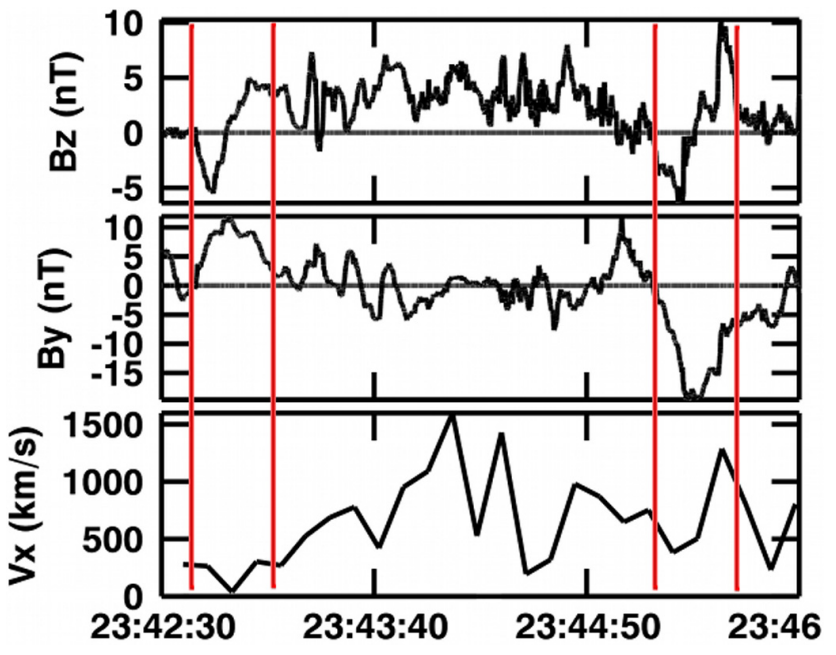

Fig. 9. Data from $\mathrm{SC} 1$ in the time interval 23:42:30-23:46:00 UT on 19 September 2003. From the top: $B_{\mathrm{z}}$ component, $B_{\mathrm{y}}$ component and ion velocity $\mathrm{X}$ component. The intervals between the red vertical lines contain the two flux ropes identified in this time period. Their core fields are of opposite polarity.

each encounter, and the IMF $B_{\mathrm{y}}$ three hour average (red) and the maximum core field measured for each flux rope (yellow crosses) are also included for comparison. The four guide field estimates for most encounters seemed to roughly follow the trend of the IMF $B_{\mathrm{y}}$ estimate, with some exceptions. However, as also seen in Fig. 7, the core field values did not correlate strongly with the IMF $B_{\mathrm{y}}$ or guide field estimates.

As mentioned above, if the guide field and/or IMF $B_{\mathrm{y}}$ is the source of the flux rope core field, all core fields of flux ropes produced in the same area within a short time interval should be of the same polarity. When studying the eight reconnection encounters associated with the observation of more than one flux rope, we found two clear counterexamples. These flux ropes were produced in the same area, presumably by the same or by neighboring $X$-lines, but their core fields were of opposite polarity. One of the two cases might be explained by a long interval between the two observations (about ten minutes). The ion reconnection outflow changed from tailward direction to earthward during this interval. The second example was harder to explain, as the two flux ropes occurred during the same ion outflow and less than three minutes apart (Fig. 9). The flux ropes had the same negative to positive $B_{\mathrm{Z}}$ bipolar signature expected at the earthward side of an $\mathrm{X}$-line $\left(V_{\mathrm{x}}^{\text {ion }}>0\right)$, but had a positive and a negative core field $\left(B_{\mathrm{y}}\right)$, respectively. The first flux rope was situated at the start of the ion reconnection outflow; the second was embedded in the middle of the flow. Geometrically, this reversal of core field polarity is most easily explained by the two observed flux ropes being part of a single U-shaped flux rope crossing the spacecraft. However, the structure of the $\mathrm{X}$-lines forming this tube is less trivial.

\section{Summary and conclusions}

In this paper we presented an analysis of magnetic flux ropes that were observed during the 21 reconnection process encounters of Borg et al. (2012). The signatures used to identify the flux ropes were (1) a bipolar GSM $B_{\mathrm{z}}$ variation, (2) a maximum or minimum (one or two peaks) in GSM $B_{\mathrm{y}}$ occurring at the center of the bipolar $B_{\mathrm{Z}}$ variation and (3) a minimum or maximum in $|B|$. The search for these signatures resulted in identification of 27 flux ropes embedded in plasma outflows of 11 of the 21 reconnection process encounters. The encounters where no flux ropes were observed were not distinguishable from other encounters with respect to duration of the encounter, the average IMF $B_{\mathrm{y}}$, the ion velocity $\mathrm{X}$ component or Hall magnetic field strength. There was also no relation between these parameters and the number of flux ropes observed during a reconnection process encounter, although the low number of available data points reduced the validity of this conclusion. Another point to remember is that the spacecraft may not have observed the entire reconnection process from start to stop. Reconnection may have been already ongoing when the spacecraft entered the region, and may have continued when the spacecraft left the region. This means that the number of flux ropes observed during each reconnection process encounter represented the minimum number of flux ropes associated with the reconnection process.

An epoch analysis of the average flux rope observed by the spacecraft showed that during flux rope observations on the earthward side of an X-line (where $V_{\mathrm{x}}^{\text {ion }}>0$ ), the $B_{\mathrm{z}}$ bipolar signature changed from negative to positive polarity, the electric field $\mathrm{Y}$ component showed a similar bipolar signature and the plasma beta reached a local minimum value during the flux rope crossing. These results agreed with the findings of Slavin et al. (2003a) and Eastwood et al. (2007). Flux ropes observed on the tailward side of an X-line had a positive to negative $B_{\mathrm{Z}}$ variation, but a less clear signature in $E_{\mathrm{y}}$ and plasma beta. The $50 \mathrm{keV}$ electron flux displayed a small local maximum at the passage of the average flux rope, but closer examination of the individual flux ropes showed that only 7 out of the 27 flux ropes contained enhanced high energy electron flux (an increase of about one order of magnitude or more compared to outside of the flux rope) in some of the PEACE and RAPID electron flux energy channels (Table 1). In contrast, simulations and studies of single $\mathrm{X}$-line encounters have suggested that electrons accelerate inside flux ropes (Drake et al., 2006a; Chen et al., 2007). On average, the electron flux inside the flux ropes was dominated by the fieldaligned component, but not more so than the electron flux in the surrounding reconnection outflow. We note that Walsh et al. (2011) have shown that field-aligned electrons are a persistent feature of the plasma sheet. Borg et al. (2012) have also shown a high degree of variability in pitch angle characteristics in the region of reconnection. The electron density increased at the middle of the average flux rope. An electron 
density maximum around the time of flux rope observation was reported in Chen et al. (2007). The ion density did not follow any specific trend around the middle of the average flux rope. Slavin et al. (2003a) reported a maximum ion density occurring ahead of the average flux rope, referring to this phenomenon as a density compression. It may be that this compression increases with increasing distance from the flux rope source and that the flux ropes analyzed in this paper were observed closer to their source than the ones observed by Geotail. However, it seems clear that the flux ropes often occurred during an ion outflow and sometimes at the start of a flow enhancement, such as the start of a reconnection outflow.

The core field, observed as a single or double peak in the $B_{\mathrm{y}}$ component measured during a flux rope crossing, got progressively more structured the closer the spacecraft crossing got to the current sheet. This agrees with the findings of Lui et al. (2007), who suggests that while the outer regions of a flux rope describe the expected helical structure, the inner regions can be more irregular in shape. This signature can also be explained by the flux rope undergoing oscillations. The origin of the core field is often contributed to the guide field by previous authors. However, as discussed above, the methods for identifying the local guide field during our reconnection outflow observations provided a range of values. These results were found to follow roughly the trend of the average IMF $B_{\mathrm{y}}$ before each X-line encounter. Comparing the polarity of the IMF $B_{\mathrm{y}}$ to the core field polarities of the flux ropes observed during the $\mathrm{X}$-line encounter did not reveal any strong relation. We also found examples of flux ropes featuring core fields of opposite polarity occurring during the same X-line encounter, and even during the same reconnection ion outflow episode. The latter could be explained if, for example, the guide field changed polarity within a short time interval, the two legs of a U-shaped flux rope crossed the spacecraft, or if parameters other than the guide field contributed to the origin of the core field. This observation remains a challenge for reconnection theory.

Acknowledgements. The authors would like to acknowledge the Cluster Active Archive and Cluster instrument teams, in particular FGM, PEACE, RAPID, EFW and CIS, for providing the Cluster data. We also acknowledge use of NASA/GSFC's Space Physics Data Facility's OMNIWeb service, and OMNI data. JPE holds an STFC Advanced Fellowship at ICL.

Topical Editor I. A. Daglis thanks C. Forsyth and J. A. Slavin for their help in evaluating this paper.

\section{References}

Asano, Y., Nakamura, R., Shinohara, I., Fujimoto, M., Takada, T., Baumjohann, W., Owen, C. J., Fazakerley, A. N., Runov, A., Nagai, T., Lucek, E. A., and Rème, H.: Electron flat-top distributions around the magnetic reconnection region, J. Geophys. Res., 113, A01207, doi:10.1029/2007JA012461, 2008.
Baker, D., Pulkkinen, T., Angelopoulos, V., Baumjohann, W., and McPherron, R.: Neutral line model of substorms: Past results and present view, J. Geophys. Res., 101, 12975-13010, doi:10.1029/95JA03753, 1996.

Balogh, A., Carr, C. M., Acuña, M. H., Dunlop, M. W., Beek, T. J., Brown, P., Fornacon, K.-H., Georgescu, E., Glassmeier, K.H., Harris, J., Musmann, G., Oddy, T., and Schwingenschuh, K.: The Cluster Magnetic Field Investigation: overview of in-flight performance and initial results, Ann. Geophys., 19, 1207-1217, doi:10.5194/angeo-19-1207-2001, 2001.

Baumjohann, W., Paschmann, G., and Lühr, H.: Characteristics of High-Speed Ion Flows in the Plasma Sheet, J. Geophys. Res., 95, 3801-3809, doi:10.1029/JA095iA04p03801, 1990.

Borg, A. L., Taylor, M. G. G. T., and Eastwood, J. P.: Electron pitch angle distribution during magnetic reconnection diffusion region observations in the Earth's magnetotail, Ann. Geophys., 30, 109117, doi:10.5194/angeo-30-109-2012, 2012.

Chen, L.-J., Bhattacharjee, A., Puhl-Quinn, P. A., Yang, H., Bessho, N., Imada, S., Mühlbachler, S., Daly, P. W., Lefebvre, B., Khotyaintsev, Y., Vaivads, A., Fazakerley, A., and Georgescu, E.: Observation of energetic electrons within magnetic islands, Nature Physics, 4, 19-23, doi:10.1038/nphys777, 2007.

Daughton, W., Scudder, J., and Karimabadi, H.: Fully kinetic simulations of undriven magnetic reconnection with open boundary conditions, Phys. Plasmas 13, 072101, doi:10.1063/1.2218817, 2006.

Deng, X. H., Matsumoto, H., Kojima, H., Mukai, T., Anderson, R. R., Baumjohann, W., and Nakamura, R.: Geotail encounter with reconnection diffusion region in the Earth's magnetotail: Evidence of multiple X lines collisionless reconnection?, J. Geophys. Res., 109, A05206, doi:10.1029/2003JA010031, 2004.

Drake, J. F., Swisdak, M., Che, H., and Shay, M. A.: Electron acceleration from contracting magnetic islands during reconnection, Nature, 443, 553-556, doi:10.1038/nature05116, 2006a.

Drake, J. F., Swisdak, M., Schoeffler, K. M., Rogers, B. N., and Kobayashi, S.: Formation of secondary islands during magnetic reconnection, Geophys. Res. Lett., 33, L13105, doi:10.1029/2006GL025957, 2006b.

Eastwood, J. P., Sibeck, D. G., Slavin, J. A., Goldstein, M. L., Lavraud, B., Sitnov, M., Imber, S., Balogh, A., Lucek, E. A., and Dandouras, I.: Observations of multiple X-line structure in the Earth's magnetotail current sheet: A Cluster case study, Geophys. Res. Lett., 32, L11105, doi:10.1029/2005GL022509, 2005.

Eastwood, J. P., Phan, T.-D., Mozer, F. S. Shay, M. A., Fujimoto, M., Retinò, A., Hesse, M., Balogh, A., Lucek, E. A., and Dandouras, I.: Multi-point observations of the Hall electromagnetic field and secondary island formation during magnetic reconnection, J. Geophys. Res., 112, A06235, doi:10.1029/2006JA012158, 2007.

Eastwood, J. P., Phan, T. D., Bale, S. D., and Tjulin, A.: Observations of turbulence generated by magnetic reconnection, Phys. Rev. Lett., 102, 035001, doi:10.1103/PhysRevLett.102.035001, 2009.

Eastwood, J. P., Phan, T. D., Øieroset, M., and Shay, M. A.: Average properties of the magnetic reconnection ion diffusion region in the Earth's magnetotail: The 2001-2005 Cluster observations and comparison with simulations, J. Geophys. Res., 115, A08215, doi:10.1029/2009JA014962, 2010a.

Eastwood, J. P., Shay, M. A., Phan, T. D., and Øieroset, M.: Asymmetry of the Ion Diffusion Region Hall Electric and Mag- 
netic Fields during Guide Field Reconnection: Observations and Comparison with Simulations, Phys. Rev. Lett., 104, 205001, doi:10.1103/PhysRevLett.104.205001, 2010b.

Gustafsson, G., André, M., Carozzi, T., Eriksson, A. I., Fälthammar, C.-G., Grard, R., Holmgren, G., Holtet, J. A., Ivchenko, N., Karlsson, T., Khotyaintsev, Y., Klimov, S., Laakso, H., Lindqvist, P.-A., Lybekk, B., Marklund, G., Mozer, F., Mursula, K., Pedersen, A., Popielawska, B., Savin, S., Stasiewicz, K., Tanskanen, P., Vaivads, A., and Wahlund, J.-E.: First results of electric field and density observations by Cluster EFW based on initial months of operation, Ann. Geophys., 19, 1219-1240, doi:10.5194/angeo19-1219-2001, 2001.

Hughes, W. J. and Sibeck, D. G.: On the 3-dimensional structure of plasmoids, Geophys. Res. Lett., 14, 636-639, doi:10.1029/GL014i006p00636, 1987.

Johnstone, A. D., Alsop, C., Burge, S., Carter, P. J., Coates, A. J., Coker, A. J., Fazakerley, A. N., Grande, M., Gowen, R. A., Gurgiolo, C., Hancock, B. K., Narheim, B., Preece, A., Sheather, P. H., Winningham, J. D., and Woodliffe, R. D.: PEACE: A plasma electron and current experiment, Space Sci. Rev., 79, 351-398, doi:10.1023/A:1004938001388, 1997.

King, J. H. and Papitashvili, N. E.: Solar wind spatial scales in and comparisons of hourly Wind and ACE plasma and magnetic field data, J. Geophys. Res., 110, A02104, doi:10.1029/2004JA010649, 2005.

Khotyaintsev, Yu. V., Vaivads, A., André, M., Fujimoto, M., Retinò, A., and Owen, C. J.: Observations of Slow Electron Holes at a Magnetic Reconnection Site, Phys. Rev. Lett., 105, 165002, doi:10.1103/PhysRevLett.105.165002, 2010.

Laakso, H., Perry, C., McCaffrey, S., Herment, D., Allen, A. J., Harvey, C. C., Escoubet, C. P., Gruenberger, C., Taylor, M. G. G. T., and Turner, R.: Cluster Active Archive: Overview, 3-37, The Cluster Active Archive, Astrophysics and Space Science Proceedings, edited by: Laakso, H., Taylor, M. G. G. T., and Escoubet, C. P., Springer, 2010.

Lui, A. T. Y., Dunlop, M. W., Rème, H., Kistler, L. M., Gustafsson, G., and Zong, Q.-G.: Internal structure of a magnetic flux rope from Cluster observations, Geophys. Res. Lett., 34, L07102, doi:10.1029/2007GL029263, 2007.

Liu, C. X., Jin, S. P., Wei, F. S., Lu, Q. M., and Yang, H. A.: Plasmoid-like structures in multiple $X$ line Hall MHD reconnection, J. Geophys. Res., 114, A10208, doi:10.1029/2009JA014257, 2009.

Moldwin, M. and Hughes, W.: On the Formation and Evolution of Plasmoids: A Survey of ISEE 3 Geotail Data, J. Geophys. Res., 97, 19259-19282, doi:10.1029/92JA01598, 1992.

Möstl, C., Farrugia, C. J., Biernat, H. K., Kiehas, S. A., Nakamura, R., Ivanova, V. V., and Khotyaintsev, Y.: The structure of an earthward propagating magnetic flux rope early in its evolution: comparison of methods, Ann. Geophys., 27, 2215-2224, doi:10.5194/angeo-27-2215-2009, 2009.

Mukai, T., Fujimoto, M., Hoshino, M., Kokubun, S., Machida, S., Maezawa, K., Nishida, A., Saito, Y., Teresawa, T., and Yamamoto, T.: Structure and kinetic properties of plasmoids and their boundary regions, J. Geomagn. Geoelectr., 48, 541-560, 1996.

Nakagawa, T. and Nishida, A.: Southward magnetic field in the neutral sheet produced by wavy motions propagating in the dawn-dusk direction, Geophys. Res. Lett., 16, 1265-1268,
doi:10.1029/GL016i011p01265, 1989.

Pedersen, A., Lybekk, B., André, M., Eriksson, A., Masson, A., Mozer, F. S., Lindqvist, P.-A., Décréau, P. M. E., Dandouras, I., Sauvaud, J.-A., Fazakerley, A., Taylor, M. G. G. T., Paschmann, G., Svenes, K. R., Torkar, K., and Whipple, E.: Electron density estimations derived from spacecraft potential measurements on Cluster in tenuous plasma regions, J. Geophys. Res., 113, A07S33, doi:10.1029/2007JA012636, 2008.

Rème, H., Aoustin, C., Bosqued, J. M., Dandouras, I., Lavraud, B., Sauvaud, J. A., Barthe, A., Bouyssou, J., Camus, Th., Coeur-Joly, O., Cros, A., Cuvilo, J., Ducay, F., Garbarowitz, Y., Medale, J. L., Penou, E., Perrier, H., Romefort, D., Rouzaud, J., Vallat, C., Alcaydé, D., Jacquey, C., Mazelle, C., d'Uston, C., Möbius, E., Kistler, L. M., Crocker, K., Granoff, M., Mouikis, C., Popecki, M., Vosbury, M., Klecker, B., Hovestadt, D., Kucharek, H., Kuenneth, E., Paschmann, G., Scholer, M., Sckopke, N., Seidenschwang, E., Carlson, C. W., Curtis, D. W., Ingraham, C., Lin, R. P., McFadden, J. P., Parks, G. K., Phan, T., Formisano, V., Amata, E., Bavassano-Cattaneo, M. B., Baldetti, P., Bruno, R., Chionchio, G., Di Lellis, A., Marcucci, M. F., Pallocchia, G., Korth, A., Daly, P. W., Graeve, B., Rosenbauer, H., Vasyliunas, V., McCarthy, M., Wilber, M., Eliasson, L., Lundin, R., Olsen, S., Shelley, E. G., Fuselier, S., Ghielmetti, A. G., Lennartsson, W., Escoubet, C. P., Balsiger, H., Friedel, R., Cao, J.-B., Kovrazhkin, R. A., Papamastorakis, I., Pellat, R., Scudder, J., and Sonnerup, B.: First multispacecraft ion measurements in and near the Earth's magnetosphere with the identical Cluster ion spectrometry (CIS) experiment, Ann. Geophys., 19, 1303-1354, doi:10.5194/angeo19-1303-2001, 2001.

Retinò, A., Nakamura, R., Vaivads, A., Khotyaintsev, Y., Hayakawa, T., Tanaka, K., Kasahara, S., Fujimoto, M., Shinohara, I., Eastwood, J. P., André, M., Baumjohann, W., Daly, P. W., Kronberg, E. A., and Cornilleau-Wehrlin, N.: Cluster observations of energetic electrons and electromagnetic fields within a reconnecting thin current sheet in the Earth's magnetotail, J. Geophys. Res., 113, A12215, doi:10.1029/2008JA013511, 2008.

Schindler, K.: A Theory of the Substorm Mechanism, J. Geophys. Res., 79, 2803-2810, doi:10.1029/JA079i019p02803, 1974.

Shirataka, N., Fujimoto, M., Hasegawa, H., and TanDokoro, R.: Reproducing the bipolar magnetic signature at the jet leading edge by three-dimensional reconnection with nonzero guide field, J. Geophys. Res., 111, A07201, doi:10.1029/2005JA011521, 2006.

Slavin, J. A., Lepping, R. P., Gjerloev, J., Fairfield, D. H., Hesse, M., Owen, C. J., Moldwin, M. B., Nagai, T., Ieda, A., and Mukai, T.: Geotail observations of magnetic flux ropes in the plasma sheet, J. Geophys. Res., 108, 1015, doi:10.1029/2002JA009557, 2003a.

Slavin, J. A., Lepping, R. P., Gjerloev, J., Goldstein, M. L., Fairfield, D. H., Acuna, M. H., Balogh, A., Dunlop, M., Kivelson, M. G., Khurana, K., Fazakerley, A., Owen, C. J., Rème, H., and Bosqued, J. M.: Cluster electric current density measurements within a magnetic flux rope in the plasma sheet, Geophys. Res. Lett., 30, 1362, doi:10.1029/2002GL016411, 2003b.

Slavin, J. A., Tanskanen, E. I., Hesse, M., Owen, C. J., Dunlop, M. W., Imber, S., Lucek, E. A., Balogh, A., and Glassmeier, K.-H.: Cluster observations of traveling compression regions in the near-tail, J. Geophys. Res., 110, A06207, doi:10.1029/2004JA010878, 2005.

Snekvik, K., Haaland, S., Østgaard, N., Hasegawa, H., Nakamura, R., Takada, T., Juusola, L., Amm, O., Pitout, F., Rème, H., 
Klecker, B., and Lucek, E. A.: Cluster observations of a field aligned current at the dawn flank of a bursty bulk flow, Ann. Geophys., 25, 1405-1415, doi:10.5194/angeo-25-1405-2007, 2007.

Teh, W.-L., Eriksson, S., Sonnerup, B. U. Ö., Ergun, R., Angelopoulos, V., Glassmeier, K.-H., McFadden, J. P., and Bonnell, J. W.: THEMIS observations of a secondary magnetic island within the Hall electromagnetic field region at the magnetopause, Geophys. Res. Lett., 37, L21102, doi:10.1029/2010GL045056, 2010.

Walsh, A. P., Owen, C. J., Fazakerley, A. N., Forsyth, C., and Dandouras, I.: Average magnetotail electron and proton pitch angle distributions from Cluster PEACE and CIS observations, Geophys. Res. Lett., 38, L06103, doi:10.1029/2011GL046770, 2011. Wilken, B., Daly, P. W., Mall, U., Aarsnes, K., Baker, D. N., Belian, R. D., Blake, J. B., Borg, H., Büchner, J., Carter, M., Fennell, J. F., Friedel, R., Fritz, T. A., Gliem, F., Grande, M., Kecskemety, K., Kettmann, G., Korth, A., Livi, S., McKenna-Lawlor, S., Mursula, K., Nikutowski, B., Perry, C. H., Pu, Z. Y., Roeder, J., Reeves, G. D., Sarris, E. T., Sandahl, I., Søraas, F., Woch, J., and Zong, Q.-G.: First results from the RAPID imaging energetic particle spectrometer on board Cluster, Ann. Geophys., 19, 1355-1366, doi:10.5194/angeo-19-1355-2001, 2001.
Wygant, J. R., Cattell, C. A., Lysak, R., Song, Y., Dombeck, J., McFadden, J., Mozer, F. S., Carlson, C. W., Parks, G., Lucek, E. A., Balogh, A., André, M., Rème, H., Hesse, M., and Mouikis, C.: Cluster observations of an intense normal component of the electric field at a thin reconnecting current sheet in the tail and its role in the shock-like acceleration of the ion fluid into the separatrix region, J. Geophys. Res., 110, A09206, doi:10.1029/2004JA010708, 2005. 